\title{
Medical Care, Social Determinants of Health and Health Equity
}

\section{Sir Michael Marmot}

I was invited to address a meeting of the American Gynecological and Obstetrical Society four years ago. I said to my audience that if they told me that American obstetricians delivered the best obstetric care in the world, I had no reason to disbelieve them. There was a problem, however. At that time, the lifetime risk of a maternal death in the US was 1 in 1,800 .

To get a sense of where the US figure fits globally, I asked them to think of 22 women of childbearing age. If we were in Afghanistan, one of those women would die of a maternal related death. By contrast, in the best-off country on this metric, Italy, you would have to count 18,000 women to get one death, on average. The US is a good deal safer than Afghanistan, but on this particular measure it ranks behind 62 other countries (Marmot 2015). Parenthetically, the numbers have changed, but the point hasn't. In 2015, the World Bank has Sierra Leone with the highest lifetime risk of a maternal death, with one woman dying in 17; and Greece with the lowest, at one woman in 23,700. The US ranks behind 45 other countries (World Bank 2015).

I suggested further that if I invited the members of the audience to write down the characteristics of the women who died of a maternal-related cause, they would all write down versions of: the poor and socially excluded, women who were subject to discrimination or were otherwise outside the system. They would be illustrating extremes of inequalities in health.

They would be illustrating something else, too. Social determinants of health and access to health care are separable, but not separate issues in practice. By this I mean: when health professionals contemplate inequalities in health, the default position is to consider inequalities in health care. Indeed, when international agencies speak of "investing in health", they actually mean: investing in health care. Yet, when I speak of health I usually refer to social determinants of health. It is a separable issue from inequalities in access to care. Inequalities in social determinants of health are responsible for much of social inequalities in the occurrence of illness. But when people get sick they need access to high quality medical care. Inequalities in access can accentuate inequalities in health. My example of obstetric care shows that social determinants and health care may intersect.

The insight from analyses of social determinants of health is that the conditions of daily life - the conditions in which people are born, grow, live, work and age - and inequities in power, money and resources, are responsible for health inequities within and between countries (Commission on the Social Determinants of Health 2008). The implication is that action to improve health equity must involve all key sectors of government and society. Ministers of education, finance, environment, and social protection may all have power over major influences on health, and health equity.

But no group of professionals cares as much about health as do we in the health professions and health policy fields. We should broaden our gaze to embrace social determinants of health as well as health care.

Doctors and other health professionals and health policy researchers may care, but are there things that we can do? During my year as President of the World Medical Association, 2015-2016, my aim was to encourage doctors and national medical associations to be active on social determinants of health. With my colleagues at the UCL Institute of Health Equity, we prepared a report, Doctors for Health Equity, on what doctors can do (Thomas 2016).

We made recommendations in five areas: 
1. Education and training

2. Seeing the patient in a broader perspective

3. The health service as employer

4. Working in partnership

5. Advocacy

Central to these is monitoring and evaluation to ensure that actions are making a difference.

Certainly, we have generated a great deal of interest from health policy people as well as members of the health professions. Prior to the WMA report, we prepared a similar report for the UK. We received commitments from 19 medical Royal Colleges and Health Professionals Associations.

'Social determinants of health' is on the agenda. In the US, for example, 'social determinants of health' has become part of the language. There may not be great policy action at national level. There is, though, a great deal of action at the city level. In the Nordic countries, many cities and regions are acting on social determinants of health. Our European Review of Social Determinants and the Health Divide has generated much interest across Europe (Marmot 2013). PAHO has set up a Commission on Equity and Health Inequalities in the Americas which is set to report at the end of 2018 (Pan American Health Organization 2018).

At the heart of these policies and activities is a commitment to social justice: improving the health of all, and reducing avoidable social inequalities in health because it is the right thing to do.

Sir Michael Marmot, MBBS, MPH, PhD, FRCP, FFPHM, FMedSci, is the director of the Institute of Health Equity at the University College London, who previously served as the Chair of the Commission on Social Determinants of Health for the World Health Organization.

\section{References}

Commission on the Social Determinants of Health (CSDH). 2008. "Closing the Gap in a Generation: Health Equity through Action on the Social Determinants of Health. Final Report of the Commission on Social Determinants of Health." Geneva: World Health Organization. http://www.who.int/social_determinants/thecommission/finalreport/en/.

Marmot, Michael. 2013. "Review of Social Determinants and the Health Divide in the WHO European Region." Copenhagen: UCL Institute of Health Equity.

Marmot, Michael. 2015. The Health Gap. London: Bloomsbury.

Pan American Health Organization (PAHO). 2018. "PAHO Commission on Equity and Health Inequalities in the Americas Met with Officials and Civil Society in Trinidad and Tobago." Pan American Health Organization / World Health Organization, January 24, 2018. http://www.paho.org/hq/index.php?option=com_content\&view=article\&id=14059\%3Apaho-commissionon-equity-and-health-inequalities-in-the-americas-met-with-officials-and-civil-society-in-trinidad-andtobago\&catid=1443\%3Aweb-bulletins\&Itemid=135\&lang=en.

Thomas, Sara. 2016. "Doctors for Health Equity." London: UCL Institute of Health Equity. http://www.instituteofhealthequity.org/resources-reports/doctors-for-health-equity-world-medicalassociation-report

World Bank. 2015. "Lifetime Risk of Maternal Death." https://data.worldbank.org/indicator/SH.MMR.RISK?view=map 